\title{
Phase I and pharmacokinetic study of trabectedin, a DNA minor groove binder, administered as a 24 -h continuous infusion in Japanese patients with soft tissue sarcoma
}

\author{
Takafumi Ueda • Shigeki Kakunaga • Masashi Ando • \\ Kan Yonemori • Hideshi Sugiura • Kenji Yamada • \\ Akira Kawai \\ Received: 7 February 2014 / Accepted: 19 March 2014 / Published online: 3 April 2014 \\ (C) The Author(s) 2014. This article is published with open access at Springerlink.com
}

\begin{abstract}
Summary Background Trabectedin is a novel anticancer agent used to treat soft tissue sarcoma (STS). This phase I study of trabectedin was performed to determine the recommended dose for phase II studies in Japanese patients with STS. Methods Patients who had STS refractory to, or who could not tolerate, anthracycline-based chemotherapy were enrolled. The starting dose of trabectedin was $0.9 \mathrm{mg} / \mathrm{m}^{2}$, given as a 24-h continuous infusion every 21 days. The dose was escalated to $1.2 \mathrm{mg} / \mathrm{m}^{2}$ and then to $1.5 \mathrm{mg} / \mathrm{m}^{2}$, using a " $3+3$ " cohort expansion design. Plasma samples were collected for pharmacokinetic analysis. Results Fifteen patients received 1 of 3 dose levels of trabectedin. Dose-limiting toxicity occurred in two of three patients at $1.5 \mathrm{mg} / \mathrm{m}^{2}: 1$ had a grade 3 increase in creatine phosphokinase and grade 3 anorexia, and the other had grade 4 platelet count decreased. Frequent grade 3 or 4 adverse events (AEs) included elevations of alanine aminotransferase and aspartate aminotransferase and decrease in neutrophil count. The frequency and severity of AEs were clearly greater at $1.5 \mathrm{mg} / \mathrm{m}^{2}$ than at the lower doses. Pharmacokinetic analysis showed that the area under the concentration-time curve at a dose of $1.2 \mathrm{mg} / \mathrm{m}^{2}$ was adequate
\end{abstract}

\footnotetext{
T. Ueda $(\bowtie) \cdot$ S. Kakunaga

Department of Orthopaedic Surgery, Osaka National Hospital,

2-1-14 Hoenzaka, Chuo-ku, Osaka 540-0006, Japan

e-mail: uedat@onh.go.jp
}

M. Ando $\cdot$ K. Yonemori

Breast and Medical Oncology Division, National Cancer Center

Hospital, Tokyo, Japan

H. Sugiura $\cdot$ K. Yamada

Department of Orthopedics, Aichi Cancer Center Hospital, Nagoya,

Aichi, Japan

A. Kawai

Division of Musculoskeletal Oncology, National Cancer Center

Hospital, Tokyo, Japan to produce antitumor activity. A partial response was obtained in three patients with translocation-related sarcomas (1 each with myxoid liposarcoma, synovial sarcoma, and extraskeletal Ewing sarcoma). Conclusions The recommended dose of trabectedin for phase II studies is $1.2 \mathrm{mg} / \mathrm{m}^{2}$ in Japanese patients with STS. Trabectedin may be especially effective against translocation-related sarcomas.

Keywords Pharmacokinetics - Clinical trial phase I - Soft tissue sarcoma $\cdot$ Trabectedin $\cdot$ Chromosomal translocation

\section{Introduction}

Soft tissue sarcomas (STS) are a heterogeneous group of rare malignant tumors of mesenchymal origin that account for less than $1 \%$ of all adult malignancies. Chromosomal translocations are the most frequent molecular alterations in sarcomas, occurring in about $20 \%$ of cases [1]. Sarcoma translocations and the associated chimeric oncoproteins provide attractive targets for therapeutic intervention, given that these fusion proteins are critical for disease pathogenesis and tumor-cell survival, and no alternative pathways exist to avoid their blockade [2-5].

Current treatment options for patients with STS vary according to clinical stage, but include surgery, radiotherapy, and chemotherapy [6]. As for chemotherapy, doxorubicin and ifosfamide, given sequentially as single agents or in combination, have been used as standard treatment for most histologic subtypes of advanced STS to date [7], however, the outcomes of patients with advanced or metastatic sarcoma remain poor over the past two decades, with an estimated median survival of approximately 1 year from the start of first-line therapy [8-11]. Recently, pazopanib, a multitargeted tyrosine kinase inhibitor has demonstrated single-agent activity in patients 
with advanced STS subtypes, excluding liposarcomas, in a phase III trial [12]. Several guidelines have included pazopanib and other chemotherapy as options for palliative therapy $[13,14]$, but there is a paucity of high-level evidence to support.

Trabectedin is a tris tetrahydroisoquinoline alkaloid initially isolated from the marine ascidian, Ecteinascidia turbinata, and is now produced synthetically. This agent binds to the minor groove of DNA and interacts with proteins of the DNA repair machinery, disrupting the cell cycle and inhibiting cell proliferation [15]. Trabectedin has been approved in the European Union and other countries worldwide, with the exception of the United States and Japan, for the treatment of advanced STS after failure of anthracycline and ifosfamide. Some clinical guidelines recommend trabectedin as a secondline option $[13,16,17]$.

Pharmacokinetic studies of trabectedin administered as 24-h continuous infusion in patients with solid tumor showed linearity within the dose range studied $\left(0.05-1.8 \mathrm{mg} / \mathrm{m}^{2}\right)$, with large inter-patient variability and moderate intra-patient variability [18]. A population pharmacokinetic (PopPK) analysis [19] derived from 603 cancer patients who received singleagent trabectedin concluded that none of the subject covariates were significantly related to between- or within-subject variability in the plasma clearance of trabectedin. Although trabectedin is considered to have a narrow therapeutic index, evidence suggesting ethnic differences in the safety and tolerability of trabectedin remains scant. Moreover, clinical trials of trabectedin have been conducted mainly in the Caucasian patients and there is little data of trabectedin for Asian patients.

This was a phase I pharmacokinetic study of trabectedin in Japanese patients with advanced STS. The primary objective was to determine the recommended dose of trabectedin for phase II studies in Japan.

\section{Patients and methods}

Patient eligibility

Patients were eligible if they were 18 years or older with an Eastern Cooperative Oncology Group (ECOG) performance status (PS) of 0 or 1, and had a histologically confirmed diagnosis of STS and had received at least one anthracycline-based regimen and a maximum of up to four previous lines of systemic therapy for advanced disease. Hematologic, hepatic and renal function had to be confirmed based on laboratory assessment.

Patients were excluded if they had received surgery during the 4 weeks before study entry; radiotherapy or chemotherapy during the 3 weeks before study entry. Pregnant or breastfeeding women were also ineligible, as were patients who had any of the following conditions: severe complications; symptomatic brain metastasis; a history of neoplasms; pleural effusion, ascites, or pericardial fluid requiring drainage.

The study was conducted in accordance with the International Conference of Harmonization guideline for Good Clinical Practice and with the Declaration of Helsinki. The protocol was approved by an independent review board at each investigational site, and written informed consent was obtained from all patients before enrollment.

\section{Treatment plan}

Trabectedin was supplied by Taiho Pharmaceutical Co., Ltd. (Tokyo, Japan) as a lyophilized powder in glass vials. The drug was administered as a 24-h continuous intravenous infusion via a central venous access catheter. Cycles were repeated every 3 weeks until disease progression, unacceptable toxicity, or withdrawal of consent. The starting dose was $0.9 \mathrm{mg} /$ $\mathrm{m}^{2}$, which is equivalent to half of the maximum tolerated dose (MTD; $1.8 \mathrm{mg} / \mathrm{m}^{2}$ ) in a previous phase I study of solid tumors [18] conducted in France. The maximum dose level was $1.5 \mathrm{mg} / \mathrm{m}^{2}$, which is the approved dose in the European Union; a $1.2 \mathrm{mg} / \mathrm{m}^{2}$ dose was also evaluated as the midway point between 0.9 and $1.5 \mathrm{mg} / \mathrm{m}^{2}$. Dose escalation followed a $3+3$ design [20]. The MTD was defined as the minimum dose at which more than $33 \%$ patients had dose-limiting toxicity (DLT). The recommended dose for phase II clinical trials was defined as the dose level below the MTD.

\section{Assessments}

Data on demographic characteristics and medical history were collected during screening. Physical examination and vital sign and safety assessments (PS, 12-lead electrocardiography, and laboratory test) were conducted at baseline/screening and throughout treatment.

\section{Safety}

Adverse events (AEs) were graded according to the National Cancer Institute Common Toxicity Criteria (version 4.0). DLT was defined as any of the following: grade 3 decrease in platelet count requiring platelet transfusion; grade 4 decrease in platelet count; grade 4 decrease in neutrophil count lasting more than 5 days; febrile neutropenia; elevations of alanine aminotransferase (ALT) or aspartate aminotransferase (AST) to more than 5 times the upper limit of normal that do not recover to 2.5 times the upper limit of normal by day 28 ; any nonhematologic toxicity of grade $\geq 3$. 


\section{Tumor response}

Tumor response was assessed according to the Response Evaluation Criteria in Solid Tumors guidelines (version 1.1) by the investigators at screening, every 6 weeks until week 24 , and every 9 weeks thereafter.

\section{Pharmacokinetic studies}

All patients underwent plasma pharmacokinetic studies between day 1 and day 8 of the first cycle. Heparinized whole blood samples were collected before the start of infusion; 0.5 and $1.5 \mathrm{~h}$ after the start of infusion; immediately before the end of infusion; and 0.5, 1, 2, 5, 8, 24, 48, 72, and $144 \mathrm{~h}$ after the end of infusion. Plasma concentrations were measured using a miniaturized liquid chromatography/tandem mass spectrometry method as described elsewhere [21]. Pharmacokinetic variables were calculated by noncompartmental analysis methods. $\mathrm{C}_{\max }$ was obtained directly from pharmacokinetic data. The AUC up to the last observed time $\left(\mathrm{AUC}_{0-\mathrm{t}}\right)$ was calculated with the trapezoidal rule. The $\mathrm{AUC}_{0 \text {-inf }}$ was calculated as the sum of $\mathrm{AUC}_{0-\mathrm{t}}$ and the extrapolated $\mathrm{AUC}$, calculated from the terminal rate constant $\lambda z\left(C_{\text {last }} / \lambda z\right.$, where $\mathrm{C}_{\text {last }}$ is the last measured concentration). The elimination half-life $\left(\mathrm{t}_{1 / 2}\right)$ was calculated as $0.693 / \lambda \mathrm{z}$, and the total plasma clearance (CL) was calculated as the dose divided by the $\mathrm{AUC}_{0 \text {-inf }}$. The volume of distribution at steady state $\left(\mathrm{V}_{\mathrm{dss}}\right)$ was calculated by the formula $\mathrm{CL} \times \mathrm{AUMC}_{0 \text {-inf }} / \mathrm{AUC}_{0-}$ inf, in which $\mathrm{AUMC}_{0 \text {-inf }}$ is the area under the first-order moment curve.

\section{Statistical analyses}

Sample size was determined empirically, based upon a $3+3$ escalation design. Descriptive statistics were used for analyses of safety, tumor response, and pharmacokinetic variables. Safety was analyzed on the basis of data for the first 4 cycles. The data cutoff point for efficacy analysis was the end of July 2013.

\section{Results}

Patient characteristics and doses administered

Between September 2010 and September 2011, a total of 15 patients received 1 of the 3 dose levels. Patient characteristics are shown according to dose level in Table 1. As for histological type of sarcoma, fusion gene was confirmed in five patients (three patients with synovial sarcoma and 1 each with extraskeletal Ewing sarcoma and myxoid liposarcoma),
The median number of treatment cycles was 4, 4, and 2 at dose level 1,2 , and 3 , respectively.

Dose-limiting toxicity

DLT occurred in two patients at dose level 3. One patient had creatine phosphokinase (CPK) increased (grade 3) and anorexia (grade 3), and the other had platelet count decreased (grade 4). Both of these patients also had severe elevations of ALT and AST (>2,000 IU/L) with no clinically significant abnormalities of bilirubin or alkaline phosphatase and no sign of hepatic impairment. These events resolved 7 to 12 days after onset and did not meet the criteria for DLT.

\section{Toxicity}

The incidence rates of adverse drug reactions occurring in three or more patients are shown according to dose level and grade in Table 2. The incidence rate and severity of AEs related to hepatic and bone-marrow toxicity increased in a dose-related fashion. At dose level 2, a patient had a grade 4 increase in CPK, but recovered from the event after delaying initiation of the next cycle. At dose level 3, all three patients had severe increases in CPK, and rhabdomyolysis was diagnosed in 1 of these patients.

A total 13 serious AEs occurred in six patients (1 of 3 patients at dose level 1, 2 of 9 at dose level 2, and 3 of 3 at dose level 3). Platelet count decreased and anorexia developed in two or more patients. All serious AEs were attributed to trabectedin and resolved after appropriate treatment. There was no treatment-related death during the study. One patient at dose level 2 and 2 patients at dose level 3 withdrew from the study because of AEs related to trabectedin (neutrophil count decreased, rhabdomyolysis, and platelet count decreased, respectively).

\section{Pharmacokinetics}

Individual plasma concentrations of trabectedin are shown in Fig. 1, and pharmacokinetic variables are shown in Table 3. Plasma trabectedin concentrations decreased immediately after the end of infusion, and the drug was gradually eliminated. Mean AUCs increased in a dosedependent manner. In one patient given dose level 2 , the plasma trabectedin concentration abnormally rose again up to $9,900 \mathrm{pg} / \mathrm{mL} 1 \mathrm{~h}$ after the completion of infusion. Elimination at dose level 3 was slower than that at the lower dose levels.

\section{Patient responses}

The maximum number of administered treatment cycles was 7, 19, and 2 at dose level 1, 2 and 3, respectively. In the 15 
Table 1 Patient characteristics

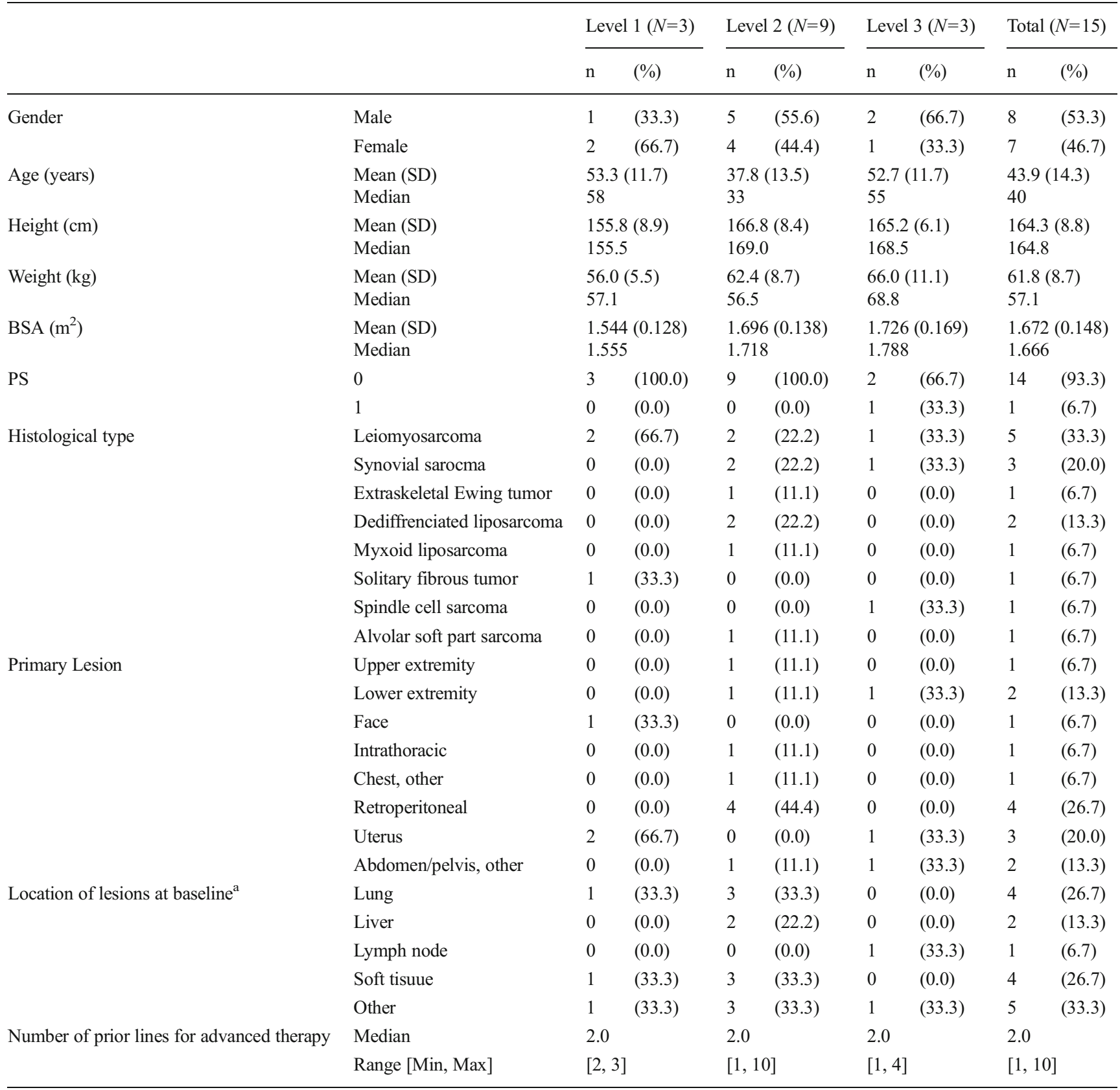

Analysis Set: FAS

$S D$ standard deviation, $P S$ performance status

${ }^{a}$ Multiple answers allowed

patients, the response rate was $20 \%$ (3 of 15) and the progression-free rate (PFR) at 3 months was $60 \%$ (9 of 15). All three patients with partial response (PR) were at dose level 2 and had translocation-related sarcomas (TRS; myxoid liposarcoma, synovial sarcoma, extraskeletal Ewing sarcoma in one patient each) with confirmation of fusion genes (EWSCHOP1, SYT-SSX1, and EWS mutation, respectively).
The case of a patient who continues the longest treatment with trabectedin is presented. A 13-year-old girl was given a diagnosis of a retroperitoneal myxoid liposarcoma in 2004. She received three lines of chemotherapy, including pirarubicin, ifosfamide, and dacarbazine, and then underwent surgery to remove the entire tumor from the pelvis. She had relapse 2 years later, underwent surgery six times, and 


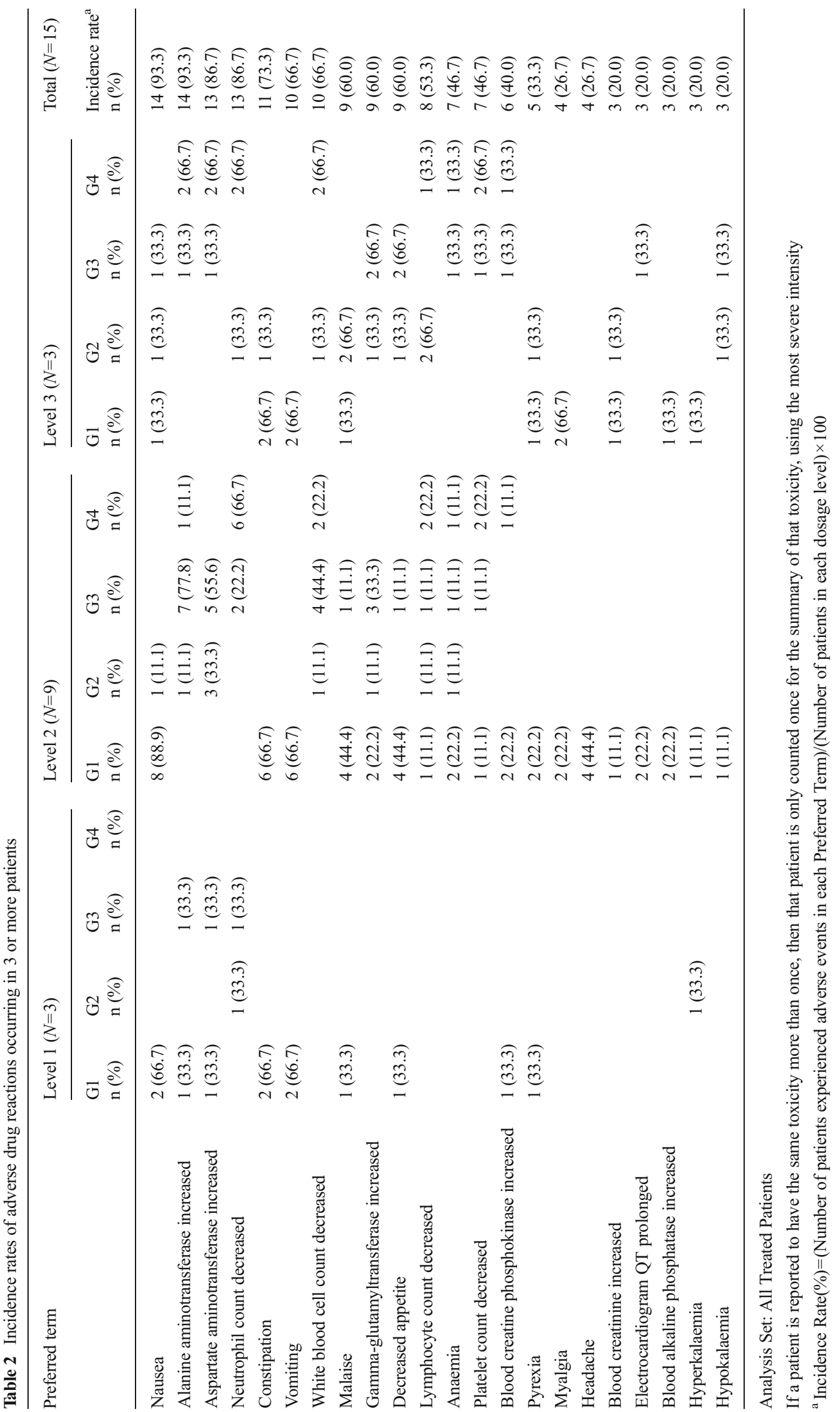




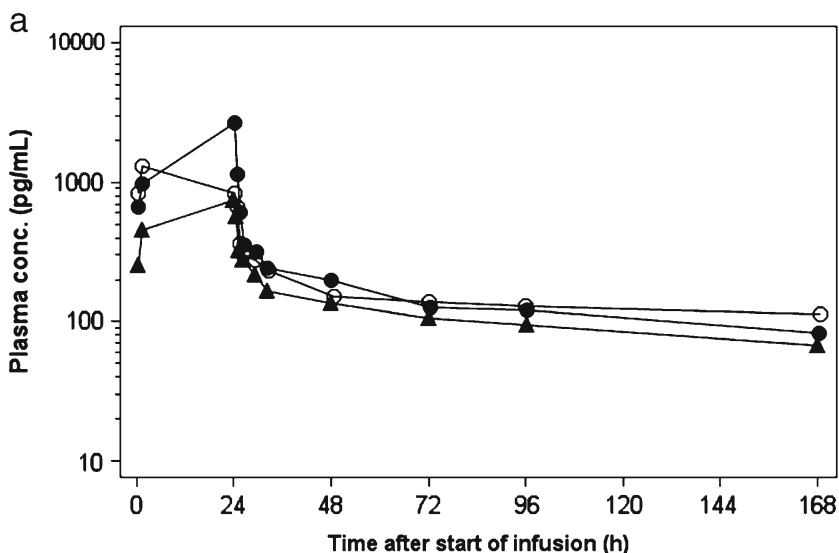

b

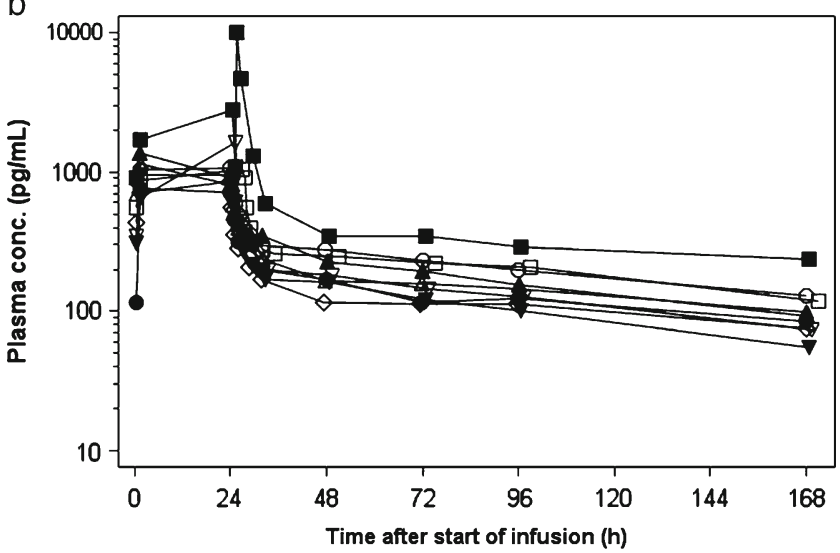

C

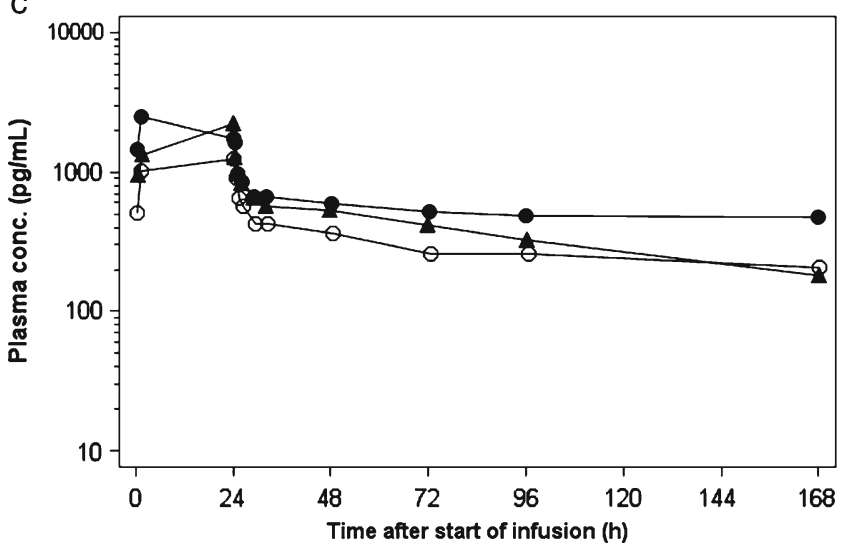

Fig. 1 Individual plasma concentration time profiles of trabectedin for a dose level 1, b dose level 2 and $\mathbf{c}$ dose level 3

received topotecan and vaccine therapy for advanced disease over the course of 5 years. When she was 21 years of age, she presented at a site participating in this study. The patient started to receive trabectedin at dose level 2 in September 2011. Magnetic resonance imaging (MRI) showed a retroperitoneal lesion (longest diameter, $249 \mathrm{~mm}$; Fig. 2a) at baseline. MRI showed a $33 \%$ reduction in tumor diameter $(167 \mathrm{~mm}$, Fig. $2 \mathrm{~b}$ ) at 7 cycles and the shortest diameter was $83 \mathrm{~mm}$ at 13 cycles (Fig. 2c). The latest diameter was $122 \mathrm{~mm}$ at 19 cycles (Fig. 2d), which meet the criteria of progressive disease (PD.

\section{Discussion}

This phase I study of trabectedin in Japanese patients with advanced STS indicated that the MTD is $1.5 \mathrm{mg} / \mathrm{m}^{2}$ and that the recommended dose for phase II clinical trials is $1.2 \mathrm{mg} / \mathrm{m}^{2}$ in Japan.

Trabectedin $1.5 \mathrm{mg} / \mathrm{m}^{2}$ as $24-\mathrm{h}$ infusion every 3 weeks is approved by the European Medicines Agency (EMA) for STS based on the results of a phase I study in patients with solid tumors [18] and a phase II study in patients with liposarcoma or leiomyosarcoma, which showed that trabectedin $1.5 \mathrm{mg} / \mathrm{m}^{2}$ every 3 weeks was associated with a longer time to progression than $0.58 \mathrm{mg} / \mathrm{m}^{2}$ every week [22].

In our study, two of three patients at dose level 3 had DLT, and the third patient had rhabdomyolysis and withdrew. All three patients also had serious AEs at dose level 3. At dose level 2, no patient had DLT. Only one patient withdrew from the study because of trabectedin-related neutrophil count decreased.

The incidence of adverse drug reactions increased in parallel to the dose of trabectedin. The number of grade 3 and 4 events including increase in hepatic transaminase and CPK was higher at dose level 3 than at dose level 1 or 2 . Based on our safety data, we estimated that $1.2 \mathrm{mg} / \mathrm{m}^{2}$ trabectedin can be administered safely to Japanese patients with STS. Thus, the present study suggested that we warn toxic expression and consider starting trabectedin treatment at $1.2 \mathrm{mg} / \mathrm{m}^{2}$ for Asian patients.

Plasma trabectedin concentrations promptly decreased after the completion of infusion, and the drug was gradually eliminated. The cause of the abnormally high drug concentration in a patient at dose level 2 is unclear, but the data were included in analysis. Owing to this high plasma concentration of trabectedin, the coefficients of variation for $\mathrm{C}_{\max }, \mathrm{AUC}_{0-\mathrm{t}}$, and $\mathrm{AUC}_{\mathrm{inf}}$ were around $50 \%$, which indicated wide variability at dose level 2. At dose level 3, high plasma trabectedin concentrations persisted after the completion of infusion in two patients who had DLTs and severe elevations of AST and ALT. Mean $\mathrm{AUC}_{0-\mathrm{t}}$ and $\mathrm{AUC}_{\text {inf }}$ were slightly higher than the respective values at the other dose levels, although $\mathrm{C}_{\max }$ was similar. The fact that two patients had severe AEs at dose level 3 may indicate a relation between pharmacokinetics and toxicity.

$\mathrm{CL}$ and $\mathrm{Vd}_{\mathrm{ss}}$ in our study were lower than the reported values (CL: $51.44 \mathrm{~L} / \mathrm{h}$ and Vdss: $4981 \mathrm{~L}$ ) in a previous phase II study in Caucasian patients with STS (PharmaMar SA, 2006). We compared our data with the reported PopPK model data in Caucasian patients [19] using visual predictive checks (VPC). Plasma concentrations in Japanese patients were slightly higher than that of the population mean estimated by the PopPK model for each dose level, and at higher dose level, 
Table 3 Pharmacokinetic parameters of trabectedin

\begin{tabular}{|c|c|c|c|c|c|c|c|c|c|c|c|}
\hline & & \multicolumn{3}{|c|}{ Level $1(N=3)$} & \multicolumn{3}{|c|}{ Level $2(N=9)$} & \multicolumn{4}{|c|}{ Level $3(N=3)$} \\
\hline & & Mean & SD & CV (\%) & Mean & SD & CV (\%) & Mean & SD & CV $(\%)$ & \\
\hline $\mathrm{t}_{\max }$ & (h) & 16.5 & 13.0 & 78.9 & 17.2 & 11.8 & 68.7 & 16.6 & 13.1 & 78.7 & \\
\hline $\mathrm{C}_{\max }$ & $(\mathrm{pg} / \mathrm{mL})$ & 1570 & 997 & 63.3 & 2070 & 2950 & 142.0 & 1990 & 652 & 32.8 & \\
\hline$\lambda z$ & $(1 / h)$ & 0.0037 & 0.0016 & 42.5 & 0.0060 & 0.0015 & 25.3 & 0.0056 & $\mathrm{NC}$ & $\mathrm{NC}$ & \\
\hline $\mathrm{t}_{1 / 2}$ & (h) & 221 & 126 & 57.2 & 124 & 35 & 28.5 & 174 & $\mathrm{NC}$ & $\mathrm{NC}$ & \\
\hline $\mathrm{AUC}_{0-48}$ & $(\mathrm{ng} \cdot \mathrm{h} / \mathrm{mL})$ & 33.3 & 15.8 & 47.5 & 35.3 & 18.5 & 52.4 & 53.5 & 14.9 & 27.8 & \\
\hline $\mathrm{AUC}_{0-\mathrm{t}}$ & $(\mathrm{ng} \cdot \mathrm{h} / \mathrm{mL})$ & 46.9 & 17.3 & 36.8 & 53.9 & 25.3 & 46.8 & 96.3 & 29.0 & 30.1 & \\
\hline $\mathrm{AUC}_{\mathrm{inf}}$ & $(\mathrm{ng} \cdot \mathrm{h} / \mathrm{mL})$ & 77.7 & 31.8 & 40.9 & 74.9 & 42.7 & 56.9 & 132 & $\mathrm{NC}$ & $\mathrm{NC}$ & \\
\hline $\mathrm{CL}$ & $\left(\mathrm{L} / \mathrm{h} / \mathrm{m}^{2}\right)$ & 13.3 & 6.4 & 47.9 & 18.7 & 5.8 & 31.0 & 11.6 & $\mathrm{NC}$ & $\mathrm{NC}$ & \\
\hline $\mathrm{Vd}_{\mathrm{ss}}$ & $\left(\mathrm{L} / \mathrm{m}^{2}\right)$ & 2470 & 1210 & 48.8 & 2030 & 716 & 35.4 & 2110 & $\mathrm{NC}$ & $\mathrm{NC}$ & \\
\hline $\mathrm{V}_{\mathrm{z}}$ & $\left(\mathrm{L} / \mathrm{m}^{2}\right)$ & 3710 & 1170 & 31.6 & 3160 & 989 & 31.3 & 2710 & $\mathrm{NC}$ & $\mathrm{NC}$ & \\
\hline $\mathrm{CL}$ & $(\mathrm{L} / \mathrm{h})$ & 21.0 & 11.7 & 55.6 & 31.4 & 9.5 & 30.1 & 21.1 & $\mathrm{NC}$ & $\mathrm{NC}$ & \\
\hline $\mathrm{Vd}_{\mathrm{ss}}$ & (L) & 3790 & 1810 & 47.6 & 3380 & 1050 & 31.0 & 3800 & $\mathrm{NC}$ & $\mathrm{NC}$ & \\
\hline $\mathrm{V}_{\mathrm{z}}$ & (L) & 5730 & 1830 & 32.0 & 5290 & 1420 & 26.8 & 4900 & $\mathrm{NC}$ & $\mathrm{NC}$ & \\
\hline
\end{tabular}

$S D$ standard deviation, $C V$ coefficients of variation

several plasma concentrations were higher than the upper range of VPC (Fig. 3a-c). Plasma concentrations at dose level 2 in our study seemed to correspond to plasma concentrations at $1.5 \mathrm{mg} / \mathrm{m}^{2}$ trabectedin in Caucasian patients (Fig. 3d). Because the clearance of trabectedin correlated with clearance of midazolam, it is apparent that the clearance of trabectedin depends on the hepatic clearance by CYP3A4 which is a main metabolism enzyme for trabectedin [23]. It is reported that there is not ethnic difference over individual difference in pharmacokinetics of midazolam [24]. Currently, the reason of the difference between Japanese and Western patients in the clearance of trabectedin is unclear.

As for the efficacy of trabectedin, the overall response rate of $20 \%$ was higher than the response rate obtained in a retrospective analysis of phase II studies of trabectedin in patients with advanced STS (7 \% among 620 patients) [25]. The PFR of $60 \%$ at 3 months also supported further investigation of this agent for STS [26]. Encouraging disease control by trabectedin was expected especially in TRS as reported previously [27].
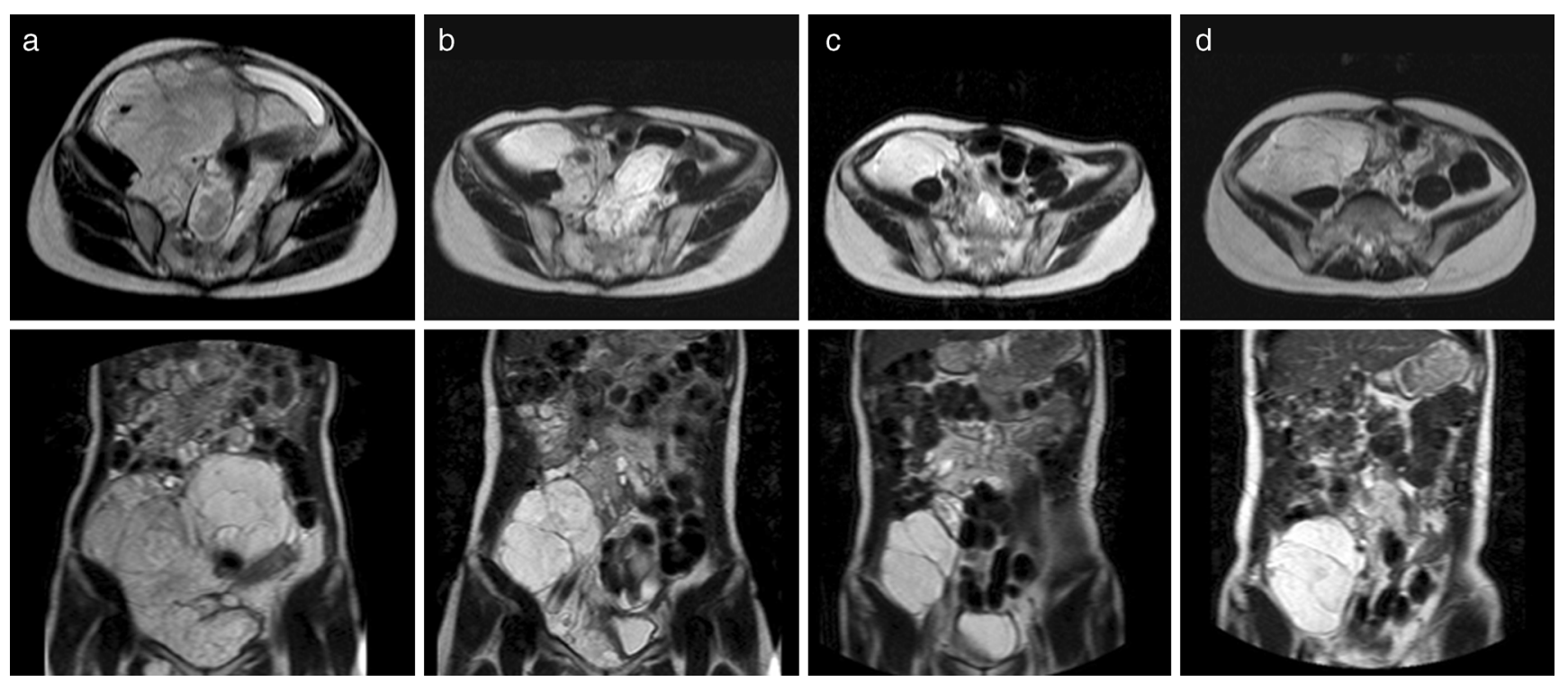

Fig. 2 MRI findings of a 21-year-old female patient with a recurrent retroperitoneal myxoid liposarcoma: a baseline, and after b 7 cycles (day 232 ), c 13 cycles (day 421) and $\mathbf{d} 19$ cycles (day 672) of trabectedin at dose level $2\left(1.2 \mathrm{mg} / \mathrm{m}^{2}\right)$ 
Fig. 3 Individual plasma concentrations of Japanese patients (red circle) over VPC $90 \%$ (blue area; data from Caucasian PopPK model at the same dose level) (25) for a dose level $1, \mathbf{b}$ dose level 2 and $\mathbf{c}$ dose level 3. d Individual plasma concentrations of Japanese patients at dose level 2 (J-1.2) over VPC $90 \%$ of Caucasian Pop PK model at $1.5 \mathrm{mg} / \mathrm{m}^{2}$ (W-1.5)
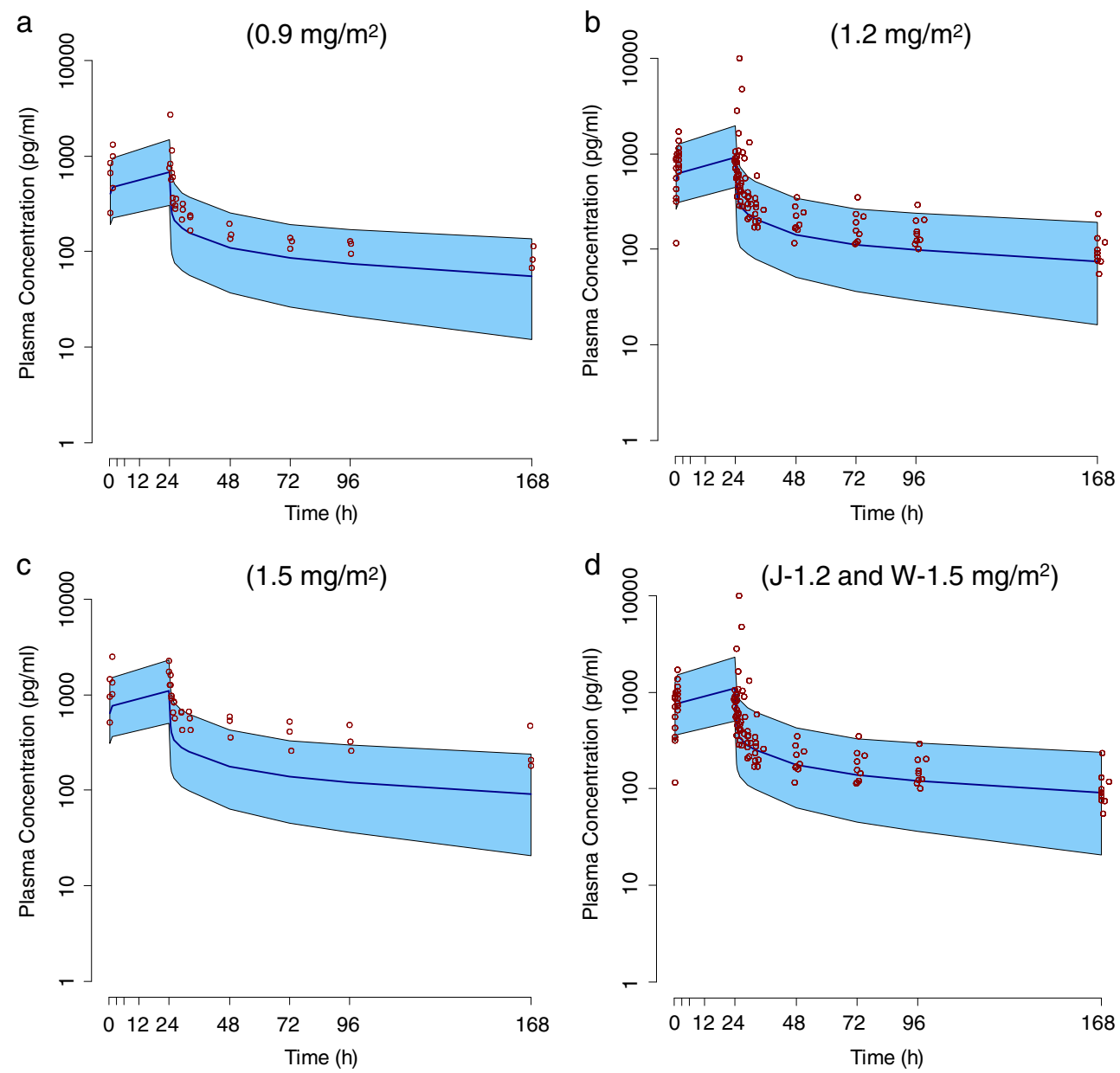

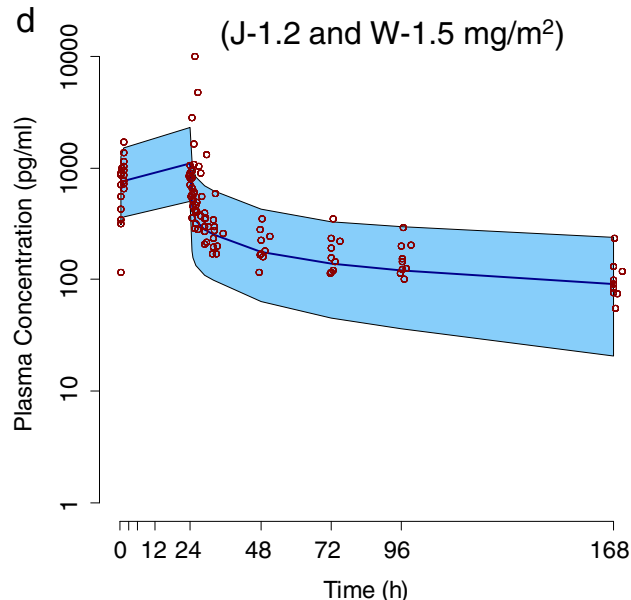

In conclusion, recommended dose of trabectedin for phase II clinical trials was $1.2 \mathrm{mg} / \mathrm{m}^{2}$ in Japanese patients with advanced STS refractory to anthracyclines. A randomized phase II study comparing $1.2 \mathrm{mg} / \mathrm{m}^{2}$ trabectedin with best supportive care is ongoing in Japanese patients with TRS. Further pharmacokinetic evaluations of trabectedin are scheduled to be performed in this phase II study to examine the reasons for the difference in the recommended dose between Japanese and Western patients.

Acknowledgments The authors would like to thank the patients and the investigators and their medical, nursing, and laboratory staff who participated in the present study. The authors also thank Carlos Fernandez Teruel and Arturo Soto Matos-Pita (Pharma Mar S.A.) for analysis and discussions concerning the comparison of our data with the pharmacokinetic data derived with the PopPK model in Caucasian patients. The authors are indebted to Peter Star of Medical Network K. K., Tokyo, Japan for his review of this manuscript.

Clinical trials This study is registered in JAPIC Clinical Trial Information, number JapicCTI-101169.

Ethical standards The study was conducted in accordance with the International Conference of Harmonization guideline for Good Clinical
Practice and with the Declaration of Helsinki. The protocol was approved by an independent review board at each investigational site, and written informed consent was obtained from all patients before enrollment.

Conflict of interest This study and editorial support for the preparation of the manuscript were funded by Taiho Pharmaceutical Co., Ltd.

T. Ueda, S. Kakunaga, M. Ando, K. Yonemori, H. Sugiura, K. Yamada and A Kawai have received contract research funding from Taiho Pharmaceutical Co, Ltd. T. Ueda is the chair of the Japanese Musculoskeletal Oncology Group (JMOG), of which Taiho Pharmaceutical Co., Ltd. is a supporting member and to which Taiho Pharmaceutical Co., Ltd. has made contributions. A. Kawai has received honoraria from Taiho Pharmaceutical Co, Ltd.

Open Access This article is distributed under the terms of the Creative Commons Attribution License which permits any use, distribution, and reproduction in any medium, provided the original author(s) and the source are credited.

\section{References}

1. Mertens F, Antonescu CR, Hohenberger P, Ladanyi M, Modena P, D'Incalci M et al (2009) Translocation-related sarcomas. Semin Oncol 36(4):312-323 
2. Ladanyi M, Bridge JA (2000) Contribution of molecular genetic data to the classification of sarcomas. Hum Pathol 31(5):532-538

3. Borden EC, Baker LH, Bell RS, Bramwell V, Demetri GD, Eisenberg BL et al (2003) Soft tissue sarcomas of adults: state of the translational science. Clin Cancer Res 9(6):1941-1956

4. Xia SJ, Barr FG (2005) Chromosome translocations in sarcomas and the emergence of oncogenic transcription factors. Eur J Cancer 41(16):2513-2527

5. Verweij J, Baker LH (2010) Future treatment of soft tissue sarcomas will be driven by histological subtype and molecular aberrations. Eur J Cancer 46(5):863-868

6. Clark MA, Fisher C, Judson I, Thomas JM (2005) Soft-tissue sarcomas in adults. N Engl J Med 353(7):701-711

7. Milano A, Apice G, Ferrari E, Fazioli F, de Rosa V, de Luna AS et al (2006) New emerging drugs in soft tissue sarcoma. Crit Rev Oncol Hematol 59(1):74-84

8. Antman K, Crowley J, Balcerzak SP, Rivkin SE, Weiss GR, Elias A et al (1993) An intergroup phase III randomized study of doxorubicin and dacarbazine with or without ifosfamide and mesna in advanced soft tissue and bone sarcomas. J Clin Oncol 11(7):1276-1285

9. Jelic S, Kovcin V, Milanovic N, Babovic N, Kreacic M, Ristovic Z et al (1997) Randomised study of high-dose epirubicin versus highdose epirubicin-cisplatin chemotherapy for advanced soft tissue sarcoma. Eur J Cancer 33(2):220-225

10. Le Cesne A, Judson I, Crowther D, Rodenhuis S, Keizer HJ, Van Hoesel $\mathrm{Q}$ et al (2000) Randomized phase III study comparing conventional-dose doxorubicin plus ifosfamide versus high-dose doxorubicin plus ifosfamide plus recombinant human granulocyte-macrophage colonystimulating factor in advanced soft tissue sarcomas: a trial of the European Organization for Research and Treatment of Cancer/Soft Tissue and Bone Sarcoma Group. J Clin Oncol 18(14):2676-2684

11. Bramwell VH, Anderson D, Charette ML (2003) Doxorubicin-based chemotherapy for the palliative treatment of adult patients with locally advanced or metastatic soft tissue sarcoma. Cochrane Database Syst Rev 3, CD003293. doi:10.1002/14651858.cd003293

12. van der Graaf WT, Blay JY, Chawla SP, Kim DW, Bui-Nguyen B, Casali PG et al (2012) Pazopanib for metastatic soft-tissue sarcoma (PALETTE): a randomised, double-blind, placebo-controlled phase 3 trial. Lancet 379(9829): 1879-1886

13. The ESMO/European Sarcoma Network Working Group (2012) Soft tissue and visceral sarcomas: ESMO Clinical Practice Guidelines for diagnosis, treatment and follow-up. Ann Oncol 23(Suppl 7):vii92vii99

14. Soft Tissue Sarcoma (2013) National Comprehensive Cancer Network. http://www.nccn.org/professionals/physician_gls/pdf/ sarcoma.pdf. Accessed 6 Nov 2013

15. Scotto KW (2002) ET-743: more than an innovative mechanism of action. Anticancer Drugs 13(Suppl 1):S3-S6

16. National Institute for Health and Clinical Excellence (2010) NICE technology appraisal guidance 185 Trabectedin for the treatment of advanced soft tissue sarcoma. http://www.nice.org.uk/nicemedia/ live/12813/47472/47472.pdf. Accessed June 2013

17. del Muro G, Solans X, Martin Broto J, Lianes Barragan P, Cubedo Cervera R (2012) SEOM clinical guidelines for the management of adult soft tissue sarcomas. Clin Transl Oncol 14(7):541-544

18. Taamma A, Misset JL, Riofrio M, Guzman C, Brain E, Lopez Lazaro L et al (2001) Phase I and pharmacokinetic study of ecteinascidin743 , a new marine compound, administered as a 24-hour continuous infusion in patients with solid tumors. J Clin Oncol 19(5):12561265

19. Perez-Ruixo JJ, Zannikos P, Hirankarn S, Stuyckens K, Ludwig EA, Soto-Matos A et al (2007) Population pharmacokinetic meta-analysis of trabectedin (ET-743, Yondelis) in cancer patients. Clin Pharmacokinet 46(10):867-884

20. Le Tourneau C, Lee JJ, Siu LL (2009) Dose escalation methods in phase I cancer clinical trials. J Natl Cancer Inst 101(10):708720

21. Rosing H, Hillebrand MJ, Jimeno JM, Gomez A, Floriano P, Faircloth G et al (1998) Quantitative determination of Ecteinascidin 743 in human plasma by miniaturized high-performance liquid chromatography coupled with electrospray ionization tandem mass spectrometry. J Mass Spectrom 33(11):1134-1140

22. Demetri GD, Chawla SP, von Mehren M, Ritch P, Baker LH, Blay JY et al (2009) Efficacy and safety of trabectedin in patients with advanced or metastatic liposarcoma or leiomyosarcoma after failure of prior anthracyclines and ifosfamide: results of a randomized phase II study of two different schedules. J Clin Oncol 27(25):4188-4196

23. Pardo B, Salazar R, Ciruelos E, Cortes-Funes H, Garcia M, Majem M et al (2012) Phase I and pharmacokinetic study of trabectedin 3-hour infusion every three weeks in patients with advanced cancer and alteration of hepatic function. Med Oncol 29(3):2240-2250

24. Myrand SP, Sekiguchi K, Man MZ, Lin X, Tzeng RY, Teng CH et al (2008) Pharmacokinetics/genotype associations for major cytochrome P450 enzymes in native and first- and third-generation Japanese populations: comparison with Korean, Chinese, and Caucasian populations. Clin Pharmacol Ther 84(3):347-361

25. Demetri GD, Blay J, Schoffski P, Maki RG, Yovine AJ, Judson I et al (2010) Outcomes of patients (pts) with advanced soft-tissue sarcomas (STS) treated in clinical trials (CTs) versus expanded access programs (EAPs): A decade of experience with single-agent trabectedin (Tr). [2010 ASCO Annual Meeting]. J Clin Oncol 28 (15s.):(15 suppl; abstr 10029)

26. Van Glabbeke M, Verweij J, Judson I, Nielsen OS (2002) Progression-free rate as the principal end-point for phase II trials in soft-tissue sarcomas. Eur J Cancer 38(4):543-549

27. Le Cesne A, Cresta S, Maki RG, Blay JY, Verweij J, Poveda A et al (2012) A retrospective analysis of antitumour activity with trabectedin in translocation-related sarcomas. Eur J Cancer 48(16): 3036-3044 